\title{
Parent-Child Similarities in Dental Caries Rates
}

\author{
STANLEY M. GARN,* NATHANIEL H. ROWE, and DIANE C. CLARK
}

\author{
Center for Human Growth and Development and School of Dentistry, \\ University of Michigan, Ann Arbor, Michigan 48109, USA
}

Since parents and their school-aged children constitute genetically related individuals living together, parent-child decayed, missing, and filled teeth (DMFT) comparisons offer opportunities to examine the familial influence on dental caries. Appropriate designs allow exploration of the possible influence of sex, apart from sexlinkage, and comparison of caries rates in children of parental extremes. Understandably, such studies demand very large sample sizes, comparisons at narrow age intervals, and (ideally) different racial groupings.

To accomplish this, we made use of permanent tooth DMFT data on 6,580 parent-child pairs (4,075 white and 2,505 black) from the TenState Nutrition Survey of 1967-1970 (Department of Health, Education, and Welfare Publication No. HSM 72-8131), comparing age-corrected DMFT of the parents with those of their offspring, arranged by one-year intervals from ages 6 through 18. Since preliminary correlations were comparable for boys and girls, final (pooled) correlations were based on the sex of the parent alone (mother-child, father-child) and the age of the child (midpoint ages 6 through 18).

As given in the table, 52 parent-child correlations for the DMF'T were both positive and staisically significant overall, being systematically higher for 26 mother-child than for 26 father-child age pairs, a trend significant at any useful level of confidence. Similarly, parent-child

This investigation was supported by Grant No. DE $0360 \mathrm{I}$ from the National Institutes of Health, Bethesda, Md.

Received for publication October 29, 1975.

Accepted for publication April 2, 1976.

- For reprints: Center for Human Growth and De velopment, $1111 \mathrm{E}$ Catherine St, Ann Arbor, Mich 48109.
DMFT correlations were systematically higher in the black American parent-child pairs than in the corresponding white parent-child age-specific pairings. Again, there was no question of the significance of the trend toward higher parentchild DMFT correlations in the black families.

In a separate analysis, DMFT of the children were grouped according to the DMFT of their parents, comparing children of two parents both with high DMFT (High $\times$ High) and children of two parents with low DMFT (Low $\times$ Low) scores. Comparisons involved both parents with a DMFT score above the 85th percentile for age and sex and both parents with a DMFT score be'ow the 15th percentile can be summarized most simply. Children of High $\times$ High parents had DMFT scores four times higher than children of parents who both had low DMFT scores (for corresponding age, sex, and race) .

Besides the obvious relationship between the DMFT score of each parent and that of the child, as shown by the correlations and the comparisons, two factors emerge for further consideration. Mother-child similarities in the DMFT scores are sys:ematically higher than father-child similarities as previously reported (KLEIN, JADA 33: 735-743, 1946; RingrLberG, Matonski, and Kimbale, $J$ Public Health Dent 34: 174-180, 1974), a fact that does not have a simple genetic explanation. Higher parent-child DMFT correlations in blacks than in whites also bear noting, since DMFT scores are systematically lower in the black participants in the Ten. State Survey (Rowe ET AL, Pediatr 57: 457-461, 1976). In the present study, DMFT scores behave like hemoglobin level, fatness, and other diet-influenced variables in the extent of parentchild resemblance (GARN, Clark, and UlllmaN, Ecol Food Nutr 4: 57-60, 1975; Garn, Clark, and GUiRE, Ecol Food Nutr 5: 47-50, 1976).

TABLE

PARENT-CHILD SIMILARITIES IN DMFT RATES

\begin{tabular}{|c|c|c|c|c|c|c|c|c|}
\hline \multirow{3}{*}{$\begin{array}{c}\text { Age } \\
\text { (Mid- } \\
\text { point) }\end{array}$} & \multicolumn{4}{|c|}{ White Families } & \multicolumn{4}{|c|}{ Black Families } \\
\hline & \multicolumn{2}{|c|}{$\begin{array}{l}\text { Father- } \\
\text { Child }\end{array}$} & \multicolumn{2}{|c|}{$\begin{array}{l}\text { Mother- } \\
\text { Child }\end{array}$} & \multicolumn{2}{|c|}{$\begin{array}{l}\text { Father- } \\
\text { Child }\end{array}$} & \multicolumn{2}{|c|}{$\begin{array}{l}\text { Mother- } \\
\text { Child }\end{array}$} \\
\hline & $N$ & $\mathbf{r}$ & $\mathbf{N}$ & $\mathbf{r}$ & $\mathbf{N}$ & $\mathbf{r}$ & $\mathbf{N}$ & $\mathbf{r}$ \\
\hline 6 & 201 & 0.05 & 181 & 0.09 & 111 & 0.22 & 94 & 0.13 \\
\hline 7 & 211 & 0.12 & 188 & 0.17 & 125 & 0.22 & 99 & 0.37 \\
\hline 8 & 199 & 0.15 & 175 & 0.16 & 110 & 0.29 & 94 & 0.39 \\
\hline 9 & 209 & 0.22 & 175 & 0.23 & 138 & 0.24 & 111 & 0.32 \\
\hline 10 & 174 & 0.15 & 160 & 0.26 & 104 & 0.39 & 91 & 0.39 \\
\hline 11 & 208 & 0.23 & 174 & 0.20 & 118 & 0.36 & 99 & 0.11 \\
\hline 12 & 211 & 0.07 & 184 & 0.19 & 124 & 0.33 & 104 & 0.30 \\
\hline 13 & 185 & 0.22 & 161 & 0.23 & 115 & 0.17 & 97 & 0.39 \\
\hline 14 & 140 & 0.12 & 101 & 0.29 & 102 & 0.13 & 83 & 0.41 \\
\hline 15 & 128 & 0.20 & 117 & 0.43 & 113 & 0.16 & 92 & 0.36 \\
\hline 16 & I 83 & 0.25 & 110 & 0.19 & 87 & 0.35 & 83 & 0.34 \\
\hline 17 & 117 & 0.24 & 93 & 0.34 & 58 & 0.24 & 52 & 0.34 \\
\hline 18 & 71 & 0.44 & 69 & 0.51 & 57 & 0.39 & 44 & 0.65 \\
\hline Mean r & & 0.17 & & 0.23 & & 0.26 & & 0.33 \\
\hline
\end{tabular}

